Serious Games and Edutainment Applications 

Minhua Ma · Andreas Oikonomou · Lakhmi C. Jain Editors

\section{Serious Games and} Edutainment Applications

然 Springer 


\section{Editors}

Minhua Ma

The Glasgow School of Art

Digital Design Studio

The Hub

G51 1EA Glasgow

UK

m.ma@gsa.ac.uk

Lakhmi C. Jain

University of South Australia

School of Electrical and Information

Engineering

Adelaide South Australia

Australia

Lakhmi.Jain@unisa.edu.au

\author{
Andreas Oikonomou \\ University of Derby \\ E514
}

School of Computing and Mathematics

Kedleston Road

DE22 1GB Derby

UK

a.oikonomou@derby.ac.uk

ISBN 978-1-4471-2160-2

DOI 10.1007/978-1-4471-2161-9

Springer London Dordrecht Heidelberg New York

British Library Cataloguing in Publication Data

A catalogue record for this book is available from the British Library

Library of Congress Control Number: 2011939794

(C) Springer-Verlag London Limited 2011

Apart from any fair dealing for the purposes of research or private study, or criticism or review, as permitted under the Copyright, Designs and Patents Act 1988, this publication may only be reproduced, stored or transmitted, in any form or by any means, with the prior permission in writing of the publishers, or in the case of reprographic reproduction in accordance with the terms of licenses issued by the Copyright Licensing Agency. Enquiries concerning reproduction outside those terms should be sent to the publishers.

The use of registered names, trademarks, etc., in this publication does not imply, even in the absence of a specific statement, that such names are exempt from the relevant laws and regulations and therefore free for general use.

The publisher makes no representation, express or implied, with regard to the accuracy of the information contained in this book and cannot accept any legal responsibility or liability for any errors or omissions that may be made.

Printed on acid-free paper

Springer is part of Springer Science+Business Media (www.springer.com) 


\section{Preface}

My interest in the serious games began in 2005 with work on virtual reality games for post-stroke rehabilitation but was rekindled in 2009 when experimenting Second Life as a learning and teaching environment for computer game design and working with Nottingham University Hospitals on computer games intervention with mucus clearing devices for Cystic Fibrosis. Serious Games and Edutainment Applications arose from the First International Workshop on Serious Games Development and Applications at University of Derby in 2010. The event has now becomes an annual conference and is supported by the Gala European Network of Excellence in Serious Games, the TARGET project which is partially funded by the European Community under the Seventh Framework Programme, and a number of partners such as the Glasgow School of Art, University of Derby, INESC ID, and Technical University of Lisbon. This year, the annual conference (SGDA 2011) is hosted by the Technical University of Lisbon (IST/UTL), and the conference proceedings will be published by Springer-Verlag as part of the LNCS series.

Serious Games and Edutainment Applications offers an insightful introduction to the development and applications of games technologies in educational settings, with cutting edge academic research and industry updates which will inform readers current and future advances in the area. The book is divided into five parts: introduction, theories and reviews, custom-made games and case studies, use of Commercial-off-the-shelf (COTS) games in education, and social aspects and gamification.

The book will benefit academics, researchers, graduates, and undergraduates in the fields of computer games and education, educators who wish to use games technologies in their teaching, game designers and developers, game publishers, and entrepreneurs in the games industry. For academics delivering taught modules in any fields, this book can serve as a good collection of related articles to facilitate a broad understanding of this subject and as such it can become one of the handbook to help educators to select, plan, and carry out teaching using commercial or custom-made games. Professional game designers and developers who adapt off-the-shelf virtual environment for teaching and learning purposes will find some interesting examples of using 
COTS games in educational settings and guidelines on choosing a suitable game for the classroom in Part IV. The custom-made edutainment applications presented in Part III of the book may be of particular interest to those who create new edutainment applications using video games technologies and game design processes.

Glasgow, UK

Minhua Ma 


\section{Contents}

\section{Part I Introduction}

1 Innovations in Serious Games for Future Learning . . . . . . . . . 3

Minhua Ma, Andreas Oikonomou, and Lakhmi C. Jain

2 Serious Games: A New Paradigm for Education? . . . . . . . . . . 9

Sara de Freitas and Fotis Liarokapis

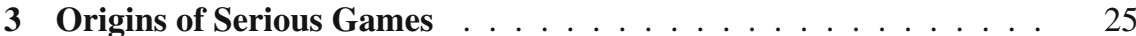

Damien Djaouti, Julian Alvarez, Jean-Pierre Jessel, and Olivier Rampnoux

4 Serious Learning in Serious Games . . . . . . . . . . . . . . . . . . 45

Konstantin Mitgutsch

\section{Part II Theories and Reviews}

5 Social Flow and Learning in Digital Games: A Conceptual

Model and Research Agenda . . . . . . . . . . . . . . . . . . . . . 61

Christine M. Bachen and Chad Raphael

6 A Formalism to Define, Assess and Evaluate Player

Behaviour in Mobile Device Based Serious Games . . . . . . . . . . 85

Hanno Hildmann and Jule Hildmann

7 Serious Games for Health and Safety Training . . . . . . . . . . . . 107

Rafael J. Martínez-Durá, Miguel Arevalillo-Herráez,

Ignacio García-Fernández, Miguel A. Gamón-Giménez, and Angel Rodríguez-Cerro

8 Augmenting Initiative Game Worlds with Mobile Digital Devices . 125 Jule Hildmann and Hanno Hildmann 


\section{Part III Custom-Made Games and Case Studies}

9 Enhancing Learning in Distributed Virtual Worlds through Touch: A Browser-based Architecture for Haptic Interaction ～. . . 149 Sylvester Arnab, Panagiotis Petridis, Ian Dunwell, and Sara de Freitas

10 Operation ARIES!: A Serious Game for Teaching Scientific Inquiry 169 Keith Millis, Carol Forsyth, Heather Butler, Patty Wallace, Arthur Graesser, and Diane Halpern

11 From Global Games to Re-contextualized Games:

The Design Process of TekMyst . . . . . . . . . . . . . . . . . . . . 197

Carolina Islas Sedano, Jan Pawlowski, Erkki Sutinen, Mikko Vinni, and Teemu H. Laine

12 Using Serious Games for Assessment . . . . . . . . . . . . . . . . . 225 Aidan Sliney and Dave Murphy

13 Designing and Evaluating Emotional Student Models for Game-Based Learning . . . . . . . . . . . . . . . . . . . . . . . 245 Karla Muñoz, Paul Mc Kevitt, Tom Lunney, Julieta Noguez, and Luis Neri

14 Fun and Learning: Blending Design and Development Dimensions in Serious Games through Narrative and Characters . . . . . . . . . . . . . . . . . . . . . . . . . . . . 273 Tim Marsh, Li Zhiqiang Nickole, Eric Klopfer, Chuang Xuejin, Scot Osterweil, and Jason Haas

Part IV Use of Commercial-Off-the-Shelf (COTS) Games in Education

15 Choosing a Serious Game for the Classroom:

An Adoption Model for Educators ～. . . . . . . . . . . . . . . . . . 291

Kae Novak and Rurik Nackerud

16 Learning Narratives with Harry Potter. "Manuel de Fallas's The Prophet Newspaper" . . . . . . . . . . . . . . . . . . . 309 Sara Cortés Gómez, Rut Martínez Borda, and Pilar Lacasa

17 Using Dungeons and Dragons to Integrate Curricula in an Elementary Classroom . . . . . . . . . . . . . . . .

Alexandra Carter

18 Modding in Serious Games: Teaching Structured Query Language (SQL) Using NeverWinter Nights . . . . . . . . . . . . . 347 Mario Soflano

19 Expanding a VLE-Based Integration Framework Supporting Education in Second Life . . . . . . . . . . . . . . . . . 369 Peter R. Bloomfield 
Part V Social Aspects and Gamification

20 Casual Social Games as Serious Games: The Psychology of Gamification in Undergraduate Education and Employee Training

Richard N. Landers and Rachel C. Callan

21 Experiences of Promoting Student Engagement Through

Game-Enhanced Learning

Therese Charles, David Bustard, and Michaela Black

22 What Computing Students Can Learn by Developing Their

Own Serious Games . . . . . . . . . . . . . . . . . . . . . . . . . . 447

Matt Smith

23 Social Interactive Learning in Multiplayer Games

Vanessa Camilleri, Leonard Busuttil, and Matthew Montebello

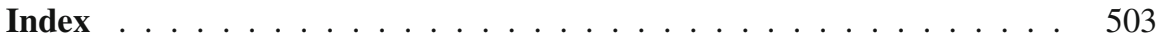





\section{Contributors}

Julian Alvarez Ludoscience, France, julian@ludoscience.com

Miguel Arevalillo-Herráez Universidad de Valencia, Computing Department, Burjassot, Spain, miguel.arevalillo@uv.es

Sylvester Arnab Serious Games Institute, Coventry University, Coventry, UK, s.arnab@coventry.ac.uk

Christine M. Bachen Communication Department, Santa Clara University, Santa Clara, CA 95053-0277, USA, cbachen@scu.edu

Michaela Black University of Ulster, Coleraine BT52 1SA, UK, mm.black@ulster.ac.uk

Peter R. Bloomfield School of Computing, University of the West of Scotland, Paisley, Scotland, UK, peter.bloomfield@uws.ac.uk

Rut Martínez Borda Department of Psychology, Education and Physical Education, University of Alcala, Madrid, Spain, rut.martinez@uah.es

David Bustard University of Ulster, Coleraine BT52 1SA, UK, dw.bustard@ulster.ac.uk

Leonard Busuttil University of Malta, Msida, Malta, leonard.busuttil@um.edu.mt

Heather Butler Claremont Graduate University, Claremont, CA, USA, heather.butler@cgu.edu

Rachel C. Callan Old Dominion University, Norfolk, VA, USA, rjohn104@odu.edu

Vanessa Camilleri University of Malta, Msida, Malta, vanessa.camilleri@um.edu.mt

Alexandra Carter University of California, Los Angeles, CA, USA, alexcarter@ucla.edu 
Therese Charles University of Ulster, Coleraine BT52 1SA, UK, theresecharles@gmail.com

Sara de Freitas Serious Games Institute (SGI), Coventry University, Coventry, UK, s.defreitas@coventry.ac.uk

Damien Djaouti IRIT, Toulouse III University, Toulouse, France; Ludoscience, France, Damien.Djaouti@irit.fr

Ian Dunwell Serious Games Institute, Coventry University, Coventry, UK, idunwell@cad.coventry.ac.uk

Carol Forsyth University of Memphis, Memphis, TN, USA, carol_forsyth@yahoo.com

Miguel A. Gamón-Giménez Instituto IRTIC, Universidad de Valencia, Paterna, Spain, Miguel.A.Gamon@uv.es

Ignacio García-Fernández Instituto IRTIC, Universidad de Valencia, Paterna, Spain, Ignacio.garcia@uv.es

Sara Cortés Gómez Department of Psychology, Education and Physical Education, University of Alcala, Madrid, Spain, sara.cortesg@uah.es

Arthur Graesser University of Memphis, Memphis, TN, USA, art.graesser@gmail.com

Jason Haas Comparative Media Studies, Massachusetts Institute of Technology, Cambridge, MA, USA, jhaas@ mit.edu

Diane Halpern Claremont McKenna College, Claremont, CA, USA, diane.halpern@claremontmckenna.edu

Hanno Hildmann Etisalat BT Innocation Centre (EBTIC), Khalifa University, Abu Dhabi, UAE; University of the West of Scotland (UWS), Scotland, UK, hanno@cypherpunx.org

Jule Hildmann Centrum für Erlebnispädagogik Volkersberg, Volkersberg, Germany, jule.hildmann@gmx.de

Carolina Islas Sedano University of Eastern Finland, FI-80101 Joensuu, Finland, carolina.islas@uef.fi

Lakhmi C. Jain School of Electrical and Information Engineering, University of South Australia, Adelaide, SA, Australia, Lakhmi.Jain@unisa.edu.au

Jean-Pierre Jessel IRIT, Toulouse III University, Toulouse, France, Jean-Pierre.Jessel@irit.fr

Paul Mc Kevitt University of Ulster, Derry/Londonderry, BT48 7JL, UK, p.mckevitt@ulster.ac.uk 
Eric Klopfer The Education Arcade, Massachusetts Institute of Technology, Cambridge, MA, USA, klopfer@mit.edu

Pilar Lacasa Department of Psychology, Education and Physical Education, University of Alcala, Madrid, Spain, p.lacasa@uah.es

Teemu H. Laine University of Eastern Finland, FI-80101 Joensuu, Finland, teemu.laine@uef.fi

Richard N. Landers Old Dominion University, Norfolk, VA, USA, rnlanders@odu.edu

Fotis Liarokapis Serious Games Institute (SGI), Coventry University, Coventry, UK, f.liarokapis@coventry.ac.uk

Tom Lunney Faculty of Computing and Engineering, School of Computing and Intelligent Systems, University of Ulster, Derry/Londonderry BT48 7JL, UK, tf.lunney@ulster.ac.uk

Minhua Ma Digital Design Studio, Glasgow School of Art, Glasgow G51 1EA, UK, m.ma@gsa.ac.uk

Tim Marsh James Cook University, QLD, Australia, tim.marsh@jcu.edu.au

Rafael J. Martínez-Durá Instituto IRTIC, Universidad de Valencia, Paterna, Spain, Rafael.Martinez@uv.es

Keith Millis Department of Psychology, Northern Illinois University, DeKalb, IL 60115, USA, kmillis@ niu.edu

Konstantin Mitgutsch Singapore-MIT Gambit Game Lab, Massachusetts Institute of Technology, Cambridge, MA 02139, USA, k_mitgut@mit.edu

Matthew Montebello University of Malta, Msida, Malta, matthew.montebello@um.edu.mt

Karla Muñoz Faculty of Computing and Engineering, School of Computing and Intelligent Systems, Intelligent Systems Research Centre, University of Ulster, Derry/Londonderry, UK, Munoz_Esquivel-K@email.ulster.ac.uk

Dave Murphy University College Cork, Cork, Ireland, d.murphy@cs.ucc.ie

Rurik Nackerud Oregon Virtual Academy, North Bend, OR 97459, USA, Rurik.Nackerud@gmail.com

Luis Neri Engineering School, Tecnológico de Monterrey (ITESM), Mexico City C.P. 14380, Mexico, neri@itesm.mx

Li Zhiqiang Nickole Ubisoft \& National University of Singapore, Singapore, Singapore, fenris_nightwolf@hotmail.com 
Julieta Noguez Computer Department, Engineering School, Tecnológico de Monterrey (ITESM), Mexico City C.P. 14380, Mexico,jnoguez@itesm.mx

Kae Novak Front Range Community College, Westminster, CO, USA, que.jinn@gmail.com

Andreas Oikonomou School of Computing and Mathematics, University of Derby, Derby DE22 1GB, UK, a.oikonomou@ derby.ac.uk

Scot Osterweil The Education Arcade, Massachusetts Institute of Technology, Cambridge, MA, USA, scot_o@mit.edu

Jan Pawlowski University of Jyväskylä, FI-40014 Jyväskylä, Finland, jan.pawlowski@jyu.fi

Panagiotis Petridis Serious Games Institute, Coventry University, Coventry, UK, ppetridis@cad.coventry.ac.uk

Olivier Rampnoux European Centre for Children's Products (CEPE), Poitiers University, Poitiers, France, olivier.rampnoux@univ-poitiers.fr

Chad Raphael Communication Department, Santa Clara University, Santa Clara, CA 95053-0277, USA, craphael@scu.edu

Angel Rodríguez-Cerro Instituto IRTIC, Universidad de Valencia, Paterna, Spain, angel.rodriguez@uv.es

Aidan Sliney University College Cork, Cork, Ireland, aidansliney@gmail.com

Matt Smith Department of Informatics, Institute of Technology Blanchardstown, Dublin 15, Republic of Ireland, matt.smith@itb.ie

Mario Soflano School of Computing, University of the West of Scotland, Paisley, Scotland, UK, Mario.Soflano@uws.ac.uk

Erkki Sutinen University of Eastern Finland, FI-80101 Joensuu, Finland, erkki.sutinen@uef.fi

Mikko Vinni University of Eastern Finland, FI-80101 Joensuu, Finland, mikko.vinni@uef.fi

Patty Wallace Northern Illinois University, DeKalb, IL, USA, pwallace@niu.edu

Chuang Xuejin National University of Singapore, Singapore, Singapore, kleken@gmail.com 


\section{About the Editors}

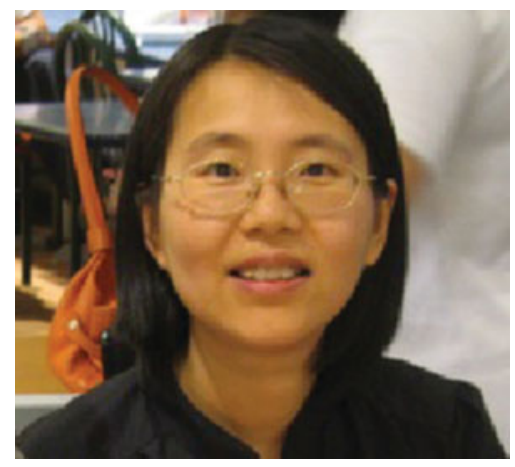

Dr. Minhua Ma is the Head of Academic Programmes at Digital Design Studio, The Glasgow School of Art. Before joining Glasgow School of Art, she was Reader in Visualisation \& Virtual Reality and Programme Leader for MSc Computer Games Production at the School of Computing and Mathematics, University of Derby. She completed her Doctorate in Computer Science from the University of Ulster in 2005, MSc in Computing Science from the University of Newcastle upon Tyne in 2001, and MA and BA in linguistics in 1998 and 1995 respectively. Her research areas include serious games, 3D visualisation, Virtual Reality, and Natural Language Processing. Her principal lines of work have been published in 50 peer-reviewed books, journals as well as conference proceedings. She has received grants from EU and East Midlands Development Agency for her work on computer games intervention with mucus clearing devices for cystic fibrosis; the Northern Ireland Chest, Heart and Stroke Association for her work on Virtual Reality in stroke rehabilitation, and a number of other grants for her research in visualisation and games.

She has been supervising $4 \mathrm{Ph}$.D. students (one completed) in video games and e-learning. With her team she has been developing serious games for healthcare and natural language 3D visualisation systems with broad impact in intelligent multimedia, serious games, forensic visualisation and other areas. Dr. Ma is the Accepting Associate Editor responsible for the serious games section of the Elsevier journal Entertainment Computing. She has been editing two books on games technology with Springer, and special issues for a couple of journals. She also authored some book chapters and organised a number of conferences and workshops in serious games and 3D visualisation. Dr. Ma is serving on the Editorial Board for the Journal of Intelligent Decision Technologies and numerous conference programme committees. 


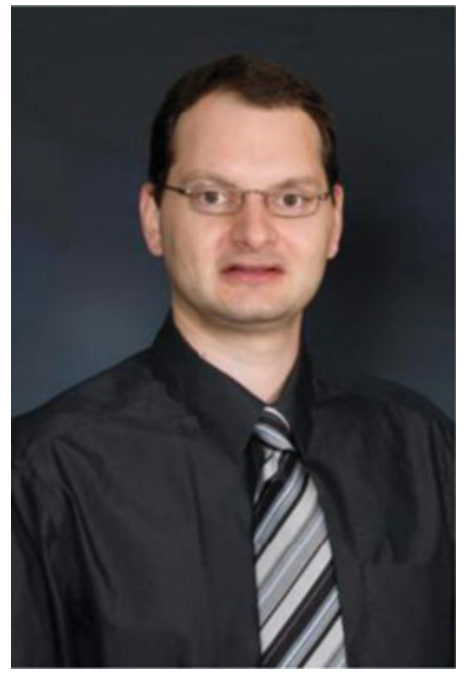

Dr. Andreas Oikonomou is Subject Coordinator and lecturer for Computer Games at the University of Derby. Prior to this appointment Dr. Oikonomou was the head of Derby Games Studio, the university's commercial games development division and has also worked as Project and Quality Assurance manager for the university's Business Development Unit. Previously to the above roles Dr. Oikonomou was multimedia and game development lecturer at Coventry University for 5 years and worked as a research assistant for the same institution for 2 years. He holds a $\mathrm{PhD}$ in Educational Multimedia Development, a Master's degree in Information Technology for Management and a BSc in Engineering. His current interests include game design, game based learning and assessment, real-time rendering, interactive multimedia, biomedical engineering and business management. Dr. Oikonomou has published 14 journal and conference papers in many aspects of biomedical computing, educational multimedia, computer games and e-learning systems development.

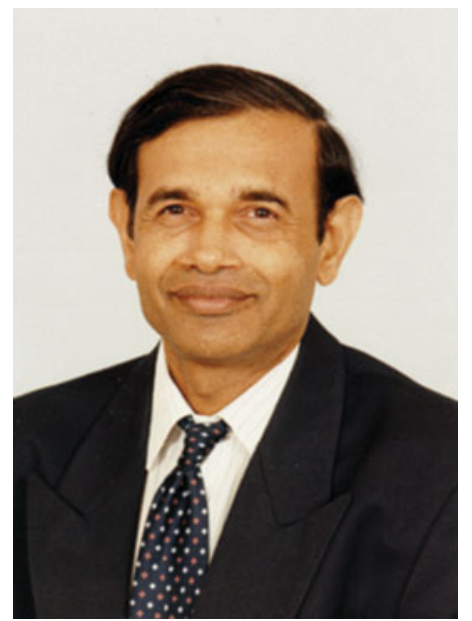

Prof. Lakhmi C. Jain is a Director/Founder of the Knowledge-Based Intelligent Engineering Systems (KES) Centre, located in the University of South Australia. He is a fellow of the Institution of Engineers Australia. His interests focus on the artificial intelligence paradigms and their applications in complex systems, art-science fusion, e-education, e-healthcare, unmanned air vehicles and intelligent agents. 